\title{
Erratum to: Efficient $(R)-3$-hydroxybutyrate production using acetyl CoA-regenerating pathway catalyzed by coenzyme A transferase
}

\author{
Ken'ichiro Matsumoto • Takehiro Okei - Inori Honma • \\ Toshihiko Ooi • Hirobumi Aoki • Seiichi Taguchi
}

Received: 20 March 2012 / Accepted: 11 April 2012 /Published online: 11 November 2012

(C) Springer-Verlag Berlin Heidelberg 2012

\section{Erratum to: Applied Microbiology and Biotechnology DOI 10.1007/s00253-012-4104-2}

We regret that the gene source of propionyl-CoA transferase was wrongly given as Clostridium propionicum whereas it should have been Megasphaera elsdenii, and that the accession number of the gene product was wrongly given as AJ276553 whereas it should have been YP_004765791.

The publishers apologise for this error

The online version of the original article can be found at http://dx.doi.org/ $10.1007 / \mathrm{s} 00253-012-4104-2$.

K. Matsumoto $(\bowtie) \cdot$ T. Okei $\cdot$ I. Honma $\cdot$ T. Ooi $\cdot$ H. Aoki $\cdot$

S. Taguchi $(\bowtie)$

Division of Biotechnology and Macromolecular Chemistry, Graduate School of Engineering, Hokkaido University,

N13W8, Kita-ku,

Sapporo 060-8628, Japan

e-mail: mken@eng.hokudai.ac.jp

e-mail: staguchi@eng.hokudai.ac.jp

H. Aoki

Corporate R\&D Center,

Showa Denko K.K. 5-1, Okawa-cho, Kawasaki-ku,

Kawasaki, Kanagawa 210-0858, Japan 